\title{
The Poor in Thomas Gray's Elegy Written in a Country Churchyard: Critical Discourse Analysis Approach
}

\author{
Hidayati $^{1}$, Zuindra ${ }^{2}$, Mayasari ${ }^{3}$, Misla Geubrina ${ }^{4}$, Arifuddin ${ }^{5}$ \\ ${ }_{1,2,3,4,5}$ Faculty of Language and Communication \\ Harapan University Medan \\ e-mail: yatihida853@gmail.com
}

Received: 03 October 2018

Accepted: 23 October 2018

\begin{abstract}
The research deals with the problems of poverty with the aim of revealing the situation of rural people experiencing various shortages throughout their daily needs. This poem is also a personal picture of the poet seeing by firsthand the situation of the marginalized people. Through critical discourse analysis by means of Van Dijk model consisting of three dimensions, namely text, social cognition and social context, the picture of the poor in the poem can be seen clearly. The data used are lines of Stanza No. 13 as a representation of the whole poem. The method used is descriptive qualitative. The results of the research indicate that knowledge or education is not limited to one group, but for all; but in practice the poor do not always get the opportunity to obtain proper education. The voice of the poor is not heard; therefore, they are bound by circumstances and cannot do much. In connection with critical discourse analysis, at the level of text, the general theme is the death and fate of the people on the periphery of the society. In the data related, the theme is the absence of opportunities for the poor to get education; the storyline starts from the causes and consequences of poverty and in the microstructure level there are syntactic and lexicon elements. The level of social cognition describes the close relationship between the poet and the elegy and of social conditions pictures the historical background of the text production.
\end{abstract}

Keywords: poverty, elegy, society, critical discourse analysis.

\section{Introduction}

Poetry, a genre in literature, cannot be separated from human life; this is in line with the literary concept stating that literature transcends national boundaries, time constraints, gender differences and even historical basis. Literature is not tied to tempora spatio, being limited by space and time. (Manugeren and Hidayati, 2018: 448).

Literature has no limit and cannot be limited by time or space. Literature is universal and goes hand in hand with the development of civilization and human culture. Literature has existed long before anyone identifies a text as a literary work. This shows that the study of literature is a discipline organizing what has existed before. Globally although literature has no restrictions but when literature enters the empirical domain, certain limitations will arise due to conventional provisions, namely the disclosure of a phenomenon based on scientific 
The Poor In Thomas Gray's Elegy Written In A Country Churchyard: Critical Discourse Analysis Approach, Hidayati, Zuindra, Mayasari, Misla Geubrina, Arifuddin

mechanisms such as observation, experiment, hypothesis, analysis and conclusion. (Teuw, 1986: 124)

Poetry is one of the works and feelings of humans through words and originally created through songs and dances and then rhyme and rhythm flowed along with the exposure of a poem. Poetic language is an emotional language, but this does not mean that poetry has no rationality. Poets express feelings through what they experience or observe from their surroundings. Poetry for most circles is the work of imagination; but it needs to be considered that an imagination is created because of the relationship with reality, especially the reality existing in a certain community. Thus, poetry is the mouthpiece of a society, or a reflection of a situation conveyed in a beautiful language. Beautiful language is also something relative; with the understanding that the beauty of a language depends on the power of thought, imagination and reason and the emotional state of the reader.

Basically, everyone has the same right to enjoy everything provided by nature because everything that is owned by humans is a gift given by God. Every human being has a certain outstanding as an extraordinary gift in carrying out life, namely the existence of the power of intuition. Intuition power is an ability possessed by every human being without the learning process, to understand what is right and wrong and determine the direction of life.

Poetry is produced based on the poet's inspiration through observation and reflection on environmental conditions. This means that the relationship of a poet with the natural environment, the social and cultural environment around him cannot be separated. The community also needs poetry not just as entertainment or media to calm the heart but also as a medium of motivation to act and behave appropriately so that life can run well. Poetry, as a literary work, also functions as social criticism; reveal the inequality that occurs in the community. Poetry brings a message to all people to be wiser in step based on love.

True beautie dwells on high: ours is a flame

But borrow'd thence to light us thither.

Beautie and beauteous words should go together. (Forerunners by

George Herbert in Piper: 2014)

The poet's duty was to perceive and communicate beauty. Beauty originates in God. It lights our little candle of beauty here as a way to lead us to God. Therefore, "beautie and beauteous words should go together." They should go together as a witness to the origin of beauty in God and as a way of leading us home to God. (Piper, 2014: 55 - 58) Meaning, message and teaching of a poem can be analyzed from various perspectives and one of which is through Critical Discourse Analysis, which is also the approach implemented in this research using the CDA model of Van Dijk.

Critical discourse analysis relates to the analysis of language without the text, meaning that critical discourse analysis studies language on a larger and more complex scale. The word discourse refers to the use of structured language produced through social interaction. This illustrates that critical discourse analysis dominates social problems through the use of language because language is a communication medium produced by a group of people as part of a community. Critical discourse analysis can also be used as a social control media through evaluating problems in the community. Through the disclosure of social problems, critical discourse analysis can provide an overview of the causes and solutions to social problems. 
The features of critical discourse analysis by Van Dijk:

1. Social process covering structures formed within is a part of discursive linguistics with the understanding that the use of language in a social interaction is a support for cultural identity and also social interaction.

2. Discourse forms a social dimension, meaning critical discourse analysis reveals the existence of a community running well or not through the social dimension obtained from the existence of social institutions in a community.

3. Language is a reflection of a certain community state.

4. Language becomes an ideology in a community; a set of ideas accepted and guided by the propriety. Language describes the consistency of a community in social interaction. (Van Dijk: 1993)

The four features of critical discourse analysis provide an illustration that critical discourse analysis is more likely to be used to express social problems. Social problems are phenomena that still exist in society. Every community group must have a problem because humans' desires are not limited while the abilities are limited and this basic concept then results in disharmony among existing social institutions.

The research deals with the portrait of the poor in Thomas Gray's Elegy Written in a Country Churchyard with the aim of giving an overview of the status and condition of the poor in the community, wherever they are.

Elegy Written in a Country Churchyard is a poem by Thomas Gray, completed in 1750 and first published in 1751. The poem is an elegy, a sad poem, embodying a meditation on the lots of the poor, providing a real picture of the sad state of rural communities with various shortcomings to meet the needs of life and they are finally marginalized and forgotten only because of their financial helplessness. They have to struggle without knowing what they stand for and life becomes bleak.

\section{Literature Review}

The principles of Critical Discourse Analysis: CDA addresses social problems; Power relations are discursive; Discourse constitutes society and culture, and is constituted by them; Discourse does ideological work: representing and constructing society by reproducing unequal relations of power; Discourse is historical and is connected to previous, contemporary and subsequent discourses; Relations between text and society are mediated, and a socio-cognitive approach is needed to understand these links; Discourse analysis is interpretive and explanatory and implies a systematic methodology and an investigation of context; Discourse is a form of social action.

To sum up, CDA is envisaged as a three-dimensional framework that examines text, discourse practice, and social practice. (Fairclough and Leitch \& Davenport in Khazraji 2018) Critical research on discourse has the following general properties, among others: It focuses primarily on social problems and political issues rather than the mere study of discourse structures outside their social and political contexts. This critical analysis of social problems is usually multidisciplinary. Rather than merely describe discourse structures, it tries to explain them in terms of properties of social interaction and especially social structure.

More specifically, CDA focuses on the ways discourse structures enact, confirm, legitimate, reproduce, or challenge relations of power abuse (dominance) in society. (Van Dijk in Tannen, et.al: 2015) Discourse is a series of texts both oral and written as a form of communication actions containing ideas from addressors to addressees based on certain 
The Poor In Thomas Gray's Elegy Written In A Country Churchyard: Critical Discourse Analysis Approach, Hidayati, Zuindra, Mayasari, Misla Geubrina, Arifuddin

contexts. (Foucault in I: 2008). By this critical discourse analysis is defined as an attempt to explain a text on social phenomena to find out the interests therein.

Then Van Dijk (1993) states that critical discourse analysis is used to clearly make senses of politics, racism, gender, social class, and hegemony. In line with the purpose of critical discourse analysis to explore social problems through discourse relations with society, critical discourse analysis is also used to understand social problems reflected in a poem. Poetry as a form of literature also reveals social problems through observations made by poets. Poetry evokes feelings and provokes thoughts about complex social issues. Poetry is more than a vehicle for expression; it is also a way of knowing. Poetry both requires and facilitates a concentration of mind or sustained attention to which our hectic lives have unaccustomed us. The linking of the strange with the familiar through the image or even through well-placed line breaks is perhaps what makes poetry so powerful. (Damico in Hughes: 2007)

Poetry is not simply a medium to express problems subjectively, but also portraits of social life delivered in a very touching language so that the reader is provoked to reflect and act proportionally to offer solutions to the existing problems. The poet not only reveals aspects about the poet's relation to society and his or her prophetic vision, but also encompass statements about the purpose of poetry ... to reach the society and move and the public. (Heyerick: 2013). So, poetry in its development, function and role is connected with various aspects and problems of human life. The problem commonly discussed through poetry is poverty. Poverty can be treated as a material concept; people are poor because they do not have something they need, or because they lack the resources to get the things they need. (Spicker, 2015)

\section{Research Method}

The research is done by means of descriptive qualitative research proposed by Cresswell (2014) aiming at interpreting social phenomena with sincere report or account having orderly procedures of research design, source of data, data collection procedure and data analysis procedure, all of which form a unity of to ease and support the whole research of the portrait of the poor in Gray's Elegy Written in a Country Churchyard by means of Critical Discourse Analysis, so that the real condition of the poor could be well pictured either through intrinsic or extrinsic approach. The primary data are taken from stanzas of the poem in the form of lines oriented to the themes of the condition of the poor.

\section{Discussion}

Gray's "Elegy Written in a Country Churchyard" is noteworthy as the poem is focused on the death, not of the great but of the layman or common people. The setting sun with gloomy atmosphere inspires the poet to reflect upon death, which comes to everyone at any moment. No one could stand against death, whether the person is rich or poor. Then a question arises in the poet's mind that pride is of no use as pride could not become a shield to lengthen life.

The word pride is often associated with rich or famous people or people with power. They are all like a mountain, which only looks beautiful from a distance. Basically, when we are close to a mountain, nothing special can be seen except the land; the same land that we see everywhere. Proud people are weak and to cover their weaknesses they become proud.

Unjust treatment experienced by poor people is an agony. 'Poor people' does not mean that they are useless. They become poor or cannot do anything significant just because they 
are not given a chance. Poor people also have greatness or potential, but in practice they are always marginalized.

The poem begins with a very beautiful picture of nature at dusk which implicitly gives a portrait of death related to the poor. If a poor person dies, nothing special can be seen; but if the rich die, the world might tremble by itself. The sun setting refers to cycle of life picturing eternity, which in essence is that everything that is born will surely experience death. There is no difference between the rich and the poor. There is nothing to be proud of or boast about during life span.

Portraits of life and the condition of the poor are very clearly illustrated in this poem. Poor people, even though they have talents or strengths, will never be considered in the community. The community assesses someone from what he has materially, not what the potential possessed. Poor people always get unfair treatment and some, especially those coming from the high level, feel reluctant to be friend the poor. Through critical discourse analysis the condition becomes clearer.

Next Gray also gives a reflection of the grave yards in the village. The cemetery reflects the social conditions of rural communities that are always beset by poverty. They cannot do much; even they cannot do anything valuable for themselves. Life feels bleak; and the future feels so floating. And all of this is better analyzed through critical discourse analysis. And the data taken to support the analysis are lines of stanza 13 represents portrait of the poor in the poem.

Critical Discourse Analysis of Van Dijk Model consists of three dimensions: Text, Social Cognition and Social Condition. The essence of van Dijk's analysis is to combine the three dimensions of discourse into a single unit of analysis. In the first text dimension, what is examined is how the structure of the text and discourse strategies are used to emphasize a particular theme. At the level of social cognition, the production process of news texts is involved which involves individual cognition from writers. Whereas the third aspect studies the building of discourse that develops in society about a problem. These three dimensions are integral and carried out together in Van Dijk's analysis.

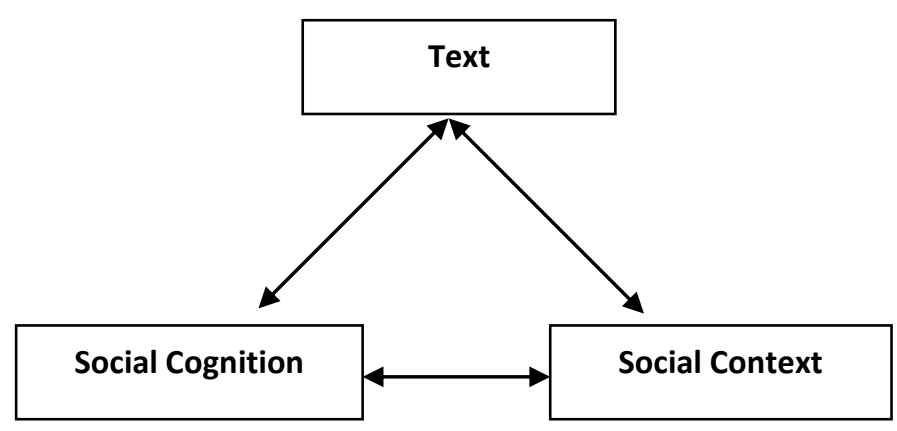

\section{Text}

Van Dijk divides the structure of the text into three levels: thematic structure. superstructure, and microstructure. Thematic structure is the global / general meaning of a text that can be observed by looking at the topic or theme that is put forward in a text. Topics are represented in one or several sentences which are the main ideas/main ideas of discourse. The topic is also said to be "semantic thematic structure".

Superstructure is a discourse structure that relates to the framework or scheme of a text, how the parts of the text are arranged in the whole news. This superstructure organizes the topic by arranging sentences or news units based on the sequence or hierarchy desired. 
The Poor In Thomas Gray's Elegy Written In A Country Churchyard: Critical Discourse Analysis Approach, Hidayati, Zuindra, Mayasari, Misla Geubrina, Arifuddin

Text or discourse generally has a scheme or plot from introduction to end. Microstructure is the meaning of discourse that can be observed from a small part of a text, namely words, sentences, paraphrases and others; in short termed linguistic elements, consisting of: syntactic element (coherence, and sentence form) semantic element (setting, details, purpose, presupposition and nominalization), lexicon element (diction), rhetoric element (graphic, metaphor).

\begin{tabular}{|c|}
\hline TEXT \\
\hline $\begin{array}{c}\text { Thematic Structure } \\
\text { (Theme of a Text) }\end{array}$ \\
\hline $\begin{array}{c}\text { Superstructure } \\
\text { (Chronological order framing a text) }\end{array}$ \\
\hline Microstructure \\
(syntactic, semantic and lexicon elements)
\end{tabular}

At the level of social cognition, text is related to the socio-cultural background as the producer of text. This refers to the mutual influences between the author and his environment.

\begin{tabular}{|l|l|}
\hline \multicolumn{2}{|c|}{ Social Cognition } \\
\hline Person Schema & One's picturing of others \\
\hline Self Schema & One being pictured by others \\
\hline Role Schema & One's view over a person in society \\
\hline Event Schema & View of events \\
\hline
\end{tabular}

Then, the level of the social context is related to the social condition of the community, which is related to how the text is formed to have an influence in it.

\begin{tabular}{|l|l|}
\hline \multicolumn{2}{|c|}{ Social Context } \\
\hline Access & How a text is formed in a surrounding \\
\hline Power & How a certain text producing power \\
\hline
\end{tabular}

\section{Data: Stanza 13}

But Knowledge to their eyes her ample page,

Rich with the spoils of time, did ne'er unroll;

Chill Penury repress'd their noble rage,

And froze the genial current of the soul.

\subsection{Text}

\subsubsection{Thematic Structure}

The most dominant theme in this poem is death; death of neglected people, who live in remote areas or in other words very poor people. The poor usually are associated with death; born to die. The next theme is mortality: that everything in life will end. The spirit of survival is also found in this poem with a picture that the poor also want to enjoy the pleasures and luxuries of life and also want to be known. Love and sympathy is also a part of the theme of this poem with a picture that longing of friends or relatives comes in time of death. In the stanza 13 the theme is related to the opportunity of the poor in getting education. 


\subsubsection{Superstructure}

The superstructure is not only focused on stanza 13 as a representative of the portrait of the poor, but also describes the storyline of the whole poem. The poem begins with a picture of nature when the sun begins to set with meditative tones on the hollowness of life owing to its mortality. Then, it moves to the simple or trivial stories of the poor but behind the simplicity the poor have, lots of moral teachings can be obtained. In the next twentyfour stanzas, this poem is related to Gray's life outlook both from personal experiences or observations. Gray comes to the end of the poem relating to the epitaph of himself. In the stanza 13, the flow starts from the existence of knowledge representing education that is open to anyone; but in reality, the poor do not have the opportunity to get a decent education and as a result they cannot easily change their destiny. Poverty makes them unable to do things that are useful for society, even though they certainly have such desires.

\subsubsection{Microstructure}

\subsubsection{Syntactic element.}

The poem is presented in a quatrain form or a four-line stanza. The first line rhymes with the third, the second with the fourth. This abab pattern is associated with elegiac poetry, making the poem in an excellent quality. Each line in each stanza is in iambic pentameter, having five pairs of syllables for a total of ten syllables. The first syllable in each pair is unaccented and the second is accented.

\subsubsection{Lexicon element}

The Lexicon element in this analysis refers to the use of poetic devices, namely figurative language commonly determined by the use of words. Gray also uses poetic devices in the poem, some of which are presented here. The use of onomatopoeia is seen in stanza 1, line 2: lowing; stanza 2, line 3: droning; stanza 3, line 2: moping; rhetorical question in stanza 11 line 2: Back to its mansion call the fleeting breath? and emphasizing statement in stanza 7 line 3: How jocund did they drive their team afield! Alliteration in stanza 1 line 3: Repetition of consonant sounds in: plow, plods; weary and way. In the data taken to support the portrait of the poor, that is stanza 13, Gray uses personification. But Knowledge to their eyes her ample page, Rich with the spoils of time did ne'er unroll, the word. Knowledge is personified by a person so is Penury.

\subsection{Social Cognition}

The poem is a record of the experience of Gray in the village of Stoke Poges and the journey of life is full of problems such as boredom, sadness, darkness and unsuccessfulness. This poem can be said as an autobiographical text because the essence is related to the fate and death that Gray has anticipated. Throughout his life, Gray is always struck by sadness and suffering; born into a broken family as Gray's father is a cruel father and husband brutally treating his children and wife. Gray writes this poem as an offering to his friend Richard West passing away in 1742. This sad tone for the death of his friend inspires this poem.

\subsection{Social Context}

The poem is written when people enter the enlightenment era, namely the development in technology. The era of rationality begins to develop and slowly defeats all the irrational concept. Various scientists come in the seventeenth century and the door to 
The Poor In Thomas Gray's Elegy Written In A Country Churchyard: Critical Discourse Analysis Approach, Hidayati, Zuindra, Mayasari, Misla Geubrina, Arifuddin

technological progress begins to open and this transition period is taken very seriously by Thomas Gray. From one side the development of technology is expected to provide convenience for humans to carry out life in a very practical way; but on the other hand, there is moral degradation where individualistic traits also develop. Each individual or group only thinks about themselves and their own groups; As a result, people who have been marginalized are further cornered. The real thing is that the poor are ignored, even the voices of poor people are not heard, however good the aspirations they convey.

\section{Conclusion}

Critical discourse analysis is a proportional media in interpreting this poem. By using text analysis of Van Dijk model with three dimensions: text, social cognition and social context, the meaning contained in this poem both implicit and explicit can be interpreted properly.

Through this poem, Gray manages to show his skills with the quality of a well-organized poetic structure. Gray does not dissolve with the times with glamorous life; instead, he discusses the problem always forgotten, namely the condition of the marginal with very poor social conditions.

The poem is a transition from the neoclassic to a romantic period. The romantic elements in the poem are significant making human life worthy of analysis such as love, reflection, and natural nuances, sympathy and empathy.

Stanza 13 as a representative data from the portrait of the life of the poor requires a contemplation from everyone. Here is clearly illustrated how the poor live their lives. The main cause of poverty is the lack or absence of opportunities to get a decent education. Knowledge or education, according to Gray, is not for one class, but for everyone; which means everyone has the right to get education. This is a universal concept; but unfortunately, in practice not everyone can get the same opportunity. When it is related to the current situation, it is clear how high the cost of education is and certainly not all can afford it. This is a real phenomenon inspiring sympathy and empathy.

\section{References}

Al Khazraji, Nidaa Hussain Fahmi. (2017). Insights into CDA: Socio-cognitive Cultural Approach. International Journal of English Linguistics. Vol. 8, No. 2. 2018. Retieved from http://doi.org/10.5539/ijel.v8n2p115 on 24 September 2018.

Creswell, John W. (2014). Research Design. Los Angeles: Sage Publication.

Gray, Thomas. (2018)). Elegy Written in A Country Churchyard. Poetry Foundation. Retrieved from https://www.poetryfoundation.org/poems/44299/elegy-written-in-a-countrychurchyard on 22 September 2018.

Heyerick, Ine. (2013). Tennyson's Poetics: The Role of the Poet and the Function of Poetry. A Thesis. Faculty of Arts and Philosophy. Ghent University. Retrieved from https://lib.ugent.be/fulltxt/RUG01/002/060/297/RUG0100206029720130001 AC.pdf on 24 September 2018.

Herbert, George. (2016). Selected Poem - The Forerunners.

Hughes, Janette Dr, 2007. Poetry: A Powerful Medium for Literacy and Technology Development. What Works? Research into Practice. University of Ontario. Retrieved from http://www.edu.gov.on.ca/eng/literacynumeracy/inspire/ research/Hughes.pdf on 25 September 2018.

I, Jansen. (2008). Discourse Analysis and Foucalt's "Archeology of Knowledge". International Journal of Caring Sciences. Vol. 1, No.3. Retrieved from 
http://internationaljournalofcaringsciences.org/docs/Vol1 Issue3 01 Jansen.pdf on 22 September 2018.

Manugeren, $M$ and Hidayati 2018. Universal Concept in Literary Work through J.M. Synge's Riders to the Sea in the $1^{\text {st }}$ Annual International Conference on Language and Literature. Retrieved from KnE Social Sciences, DOI 10.18502/kss.v3i4.1958 on 11 September 2018.

Piper, John. (2014). Seeing Beauty and Saying Beautifully. Illinois: Crossway.

Spicker, Paul. (2015). Definitions of Poverty: Twelve Clusters of Meanings. ResearchGate. Retrieved from https://www.researchgate.net/publication/ 265422363 Definitions of poverty twelve clusters of meaning on 1 October 2018.

Teeuw, A. (1986). Modern Indonesian Literature. Vol. 1. Leiden: Brill

Van Dijk, Teun A. (1993). Principles of Critical Discourse Analysis. Discourse and Society. Sage Journal. Vol 4 , Issue 2.4 Retrieved from http://journals.sagepub.com/doi/10.1177/0957926593004002006. on 20 September 2018. 